\title{
Microscopic Study of the Phonograph
}

Discussion of the Mechanical Features of Record Grooves and Styluses

TW of the most remarktions, the telephone and the phonograph, were scientific an 40 years ago. Besides being nearly of the same age, they have much n common. Both depend fundamentally on the same extremely simple principle, and appreciation of this inherent simplicity may be regarded as the real invention in both cases. The construction of properly working apparatus certainly required genius and inventive ability of a high order, but of a different nature.

All speech and all music are simple from a mechanical standpoint and therefore capable of well-nigh perfect transmission by telephone, or of nearly perfect recording, preserving and reprolucin preserving and reprolucing by phonograph. H ow ever
complex, elaluorate or multiplied may be the sound-producing sources, all the waves combine at any surface, such as the ear-drum, into a single wave. Now, irrespective of how simple or complex this wave may be, the drum or diaphragm, which moves back and forth following the motion and pressure of the air against it, cannot occupy two positions at the sume time. In other words, if it were possible to write down the extent of the stretching of the ear-drum (and whether in or out) at intervals of, say, 1-10,000 second, and make the table long enough to show all these values for a whole second or a minute, it would be practicable to record and analyze, as it were, any sound. Obviously, some apparatus is needed to measure the stretching or deflection of the membrane; and since the impossibility of taking down figures so rapidly is evident, an automatic recording of the diaphragm deflection is necessary. As an artificial diaphragm of suitable size and material construction will follow sound waves in the same manner as the ear-drum, continuous records can be made with the aid of light stylus or needle attached to a diaphragm fitted with multiplying levers and bearing on a smoked glass or paper surface which is moved along at a uniform rate under the recording needle. With no sound the diaphragm is at rest and the needle draws a straight or "zero" line. Deflections caused by sounds produce a wavy or irregular line. (See Fig. 1.).
By J. B. Taylor

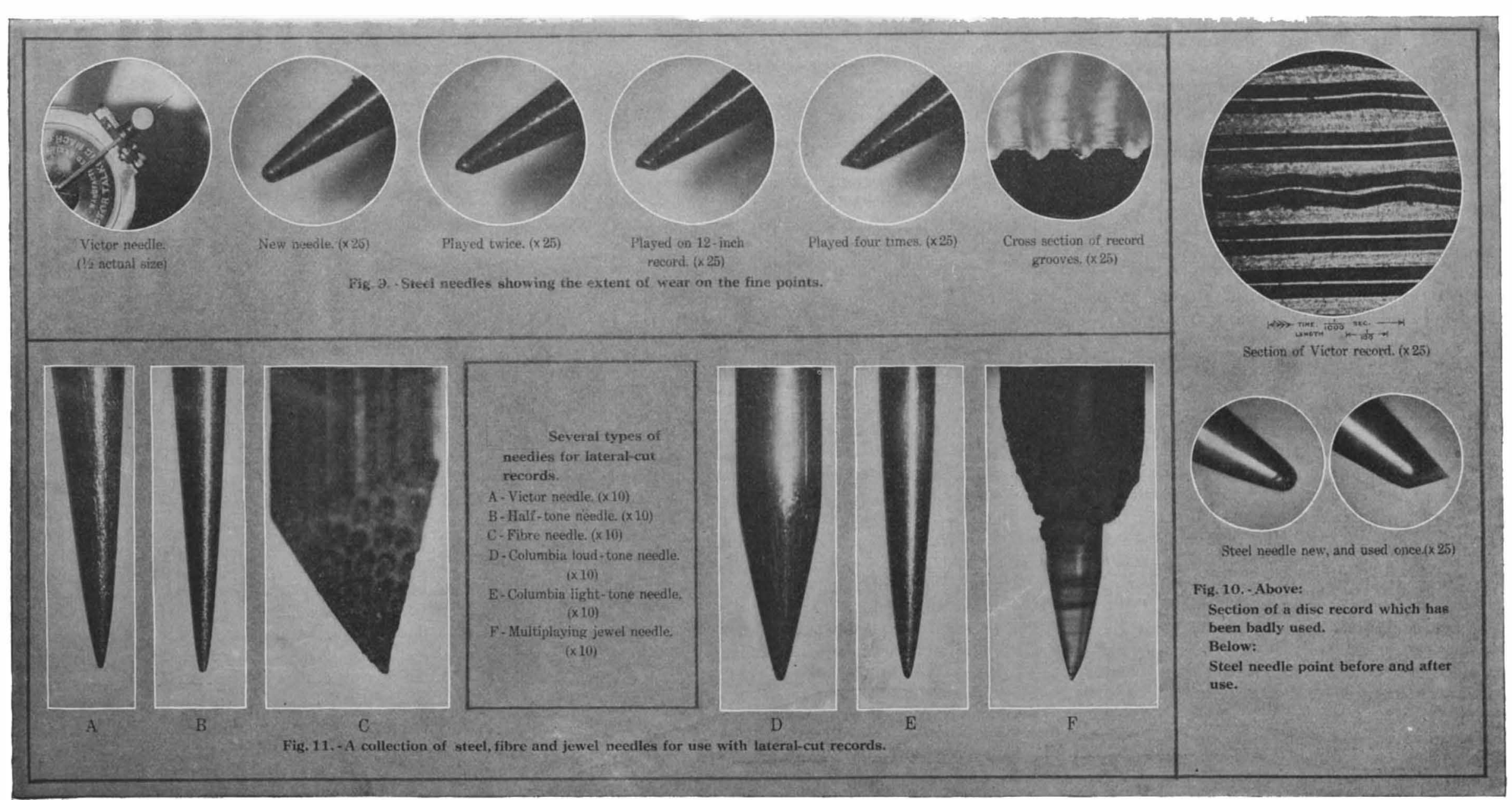

\section{Types of up-and-down cut grooves and styluses}

Such an aplaratus, the phonautograph was constructed and records made years before the telephone or phonograph was introduced. Probal) ly most of the rhonautograph records were far from accurate sound records, since such factors as size, weight and tensio of diaphragm, natural frequency of vibration, damping

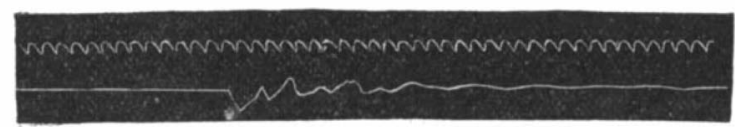

Fig. 1.-Typical records of sound waves made with a phonautograph

of vibrating parts and serious distortions due to resonance of collecting hor"l or chamber were not recos nized. Some modern apparatus for analyzing soun employs in place of the tracing stylus a light mirro which reflects and deflects a beam of light focussed to a small spot on a moving photographic plate or film. Having obtained the sound record, whether by means of smoked class, photographically or otherwise, any de-

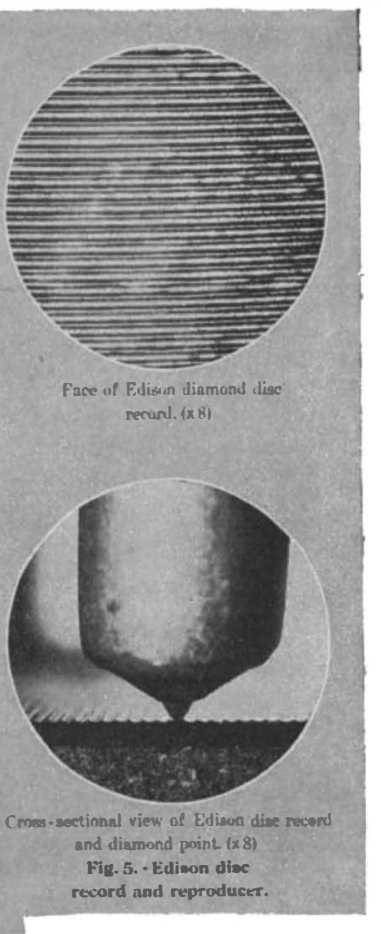

gested,一which will control the compression or rarefaction of the air to correspond with the record will reproduce the original sounds and constitute a phonograph. In the early forms of Edison's machine which were exhibited, indentations were made, by means of a steel point on a diaphragm, in a sheet of tin-foil wrapped on a revolving cylinder. The foil served both as original and reproducing record. A piece of tin-foil used at a public demonstration in England in 1878 is shown in Fig. 2. The tin-foil record soon gave way to hollow wax cylinders in which a helical groove of variable depth was cut. These were slipped over a tapered mandrel. Fig. 3 shows, magnified, the grooves of fluctuating depth of several cylinder -records, as well as those of some disc records employing the same type of groove.

In these cylinder records and in some later forms of disc records, the displacement of the stylus which connects with the diaphragm is up-and-down. Many of the well-known disc records have a groove of uniform depth in which a needle or stylus of steel or other metal, or sometimes of fibrous material, rests. Here. instead of by vertical motion, the groove receives the sound record by a lateral or side-to-side motion. Photomicrographs of a number of records of this type are shown in Fig. 7. In this motion these disc records resemble the phonautograph and oscillograph records

A microscopic study of a phonograph record for sound analyzing purposes is disappointing because the scale of time is so long and the deflections so small, relatively speaking. Compared with an oscillogram, the disc record shown in Fig. 10 is most interesting. In the oscillogram, 1-100 second takes a little more than one inch and the deflections run to one half inch. In the enlarged phonograph record, on the other hand, the time scale for $1-100$ second is 16 inches, but the deflections, although magnified 25 diameters, ${ }^{1}$ appear

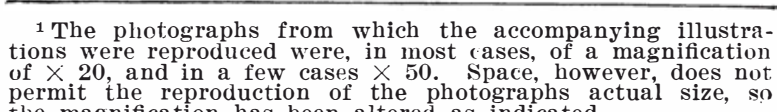
of $\times 20$, and in a few cases $\times 50$. Space, however, does not permit the reproduction of the photographs actual size, s 
as only 1-32 inch. With this relationship between time and displacements, the eye is unable to receive any proper impression of the wave shape, hence a replotting similar to the drawing of the profile of a railroad is needed for study. Such transcribed phonograph records have been made by Louis Bevier, Jr., for the vertical cut cylinder, ${ }^{1}$ while the lateral cut discs have been studied by E. W. Scripture. ${ }^{2}$

The variable depth of cut is well shown in the photomicrograph appearing in Fig. 4. This record was broken to illustrate the appearance of the sound grooves in cross-section. The cut and polished spherical sapphire used as reproducing. stylus has been placed in position in one of the grooves to show the relative dimensions and the extent of bearing surface. This is a dise record which starts to play from the inner end of the spiral grooves. There is no difficulty experienced with this record in the matter of the feed or self-propelling of the sound-box on the swinging arm across the face of the record, although the shallowness of the grooves, as shown in the cross-section, might lead one to predict trouble. The pitch here is 80 per inch that is to say, the grooves ure 1-80 inch apart.

Fig. 5 shows in similar views the face of a record and a broken cross-section of the disc with the stylus in place. In this make of record the pitch is 150 per inch and the reproducing stylus is a diamond with a rounded end ground to proper radius for the groove. Although the groove is quite as deep as that shown in Fig. 4, the makers furnish a sound-box of a construction requiring a geared mechanism to feed along the reproducing soundbox and the connections to the resonating horn. In the cross-sectional view there is clearly shown the composite structure of the record. As the magnification is eight dithe magn urface layer is but little more than 1-100 inch thick and of a material better suited than the base or filling material to mould to the "master" in the process of manufacturing and to stand the wear of tre reproducing stylus.

In the vertical cut or hilland-dale types of record, the recording stylus-more prope ly a cutting tool-has a circular cutting edge; the crosssection of the groove being practically the somment of a circle and differing but slightly from the circular curve because the elge of tool, as shown in Fig. 6, works at an angle to the record receiving surface. The

circular curve is advintugeous because hard substances, such as sapphire and diamond, can be worked and polished readily to any given circular and spherical dimensions. Working to other shapes and curves is more expensive and less exact.

Fig. 6 shows two sizes of recording sapphires and the corresponding spherical reproducing sapphires. The bearing of the sphere in the groove of the record is on as the depth of and when the sphere is on the tops of the "hills." When changing grade and when resting on the bottom of the "valleys," the bearing will be on a surface-one or the other o even both sides of the normal bearing line making contact, and if the hills are short and steep, as occur with loud tones of high pitch, the spherical sapphire may bridge parts of the valleys. To reduce this bridging and secure better tone quality without increasing the diameter or the speed of a cylinder record, the button-shaped sapphire illustrated has been used.

The faces of six lateral cut records are shown, magnified 15 diameters, in Fig. 7 . Three of these are familiar large sized records, while the remaining three are small sized novelties. The inferior tone of these

1 Physical Review, Appril, 1900, et seq.
2 Publication No. 44, Carnegie Institution of Washington, cheap novelty records is readily understood by comparing the rough edges of the grooves with the clean cut edges of the larger and more expensive records. Furthermore, the smallest of these novelties are physically incapable of rendering the higher frequency musical tones, since the small dimensions make the wave lengths at normal speed comparable with and even less than the bearing length of the recording needle. The charactor of the groove in the lateral cut type of record can be made out from Figs. 8 and 10 . Fis. 8 shows the face of a record and a broken cross-section with the point of the steel reproducing needle in working position in one of the grooves. This is a make of record which the cross-section proves to be composite. Surface layers of about 1-75 inch in thickness are$$
\text { (2) }
$$
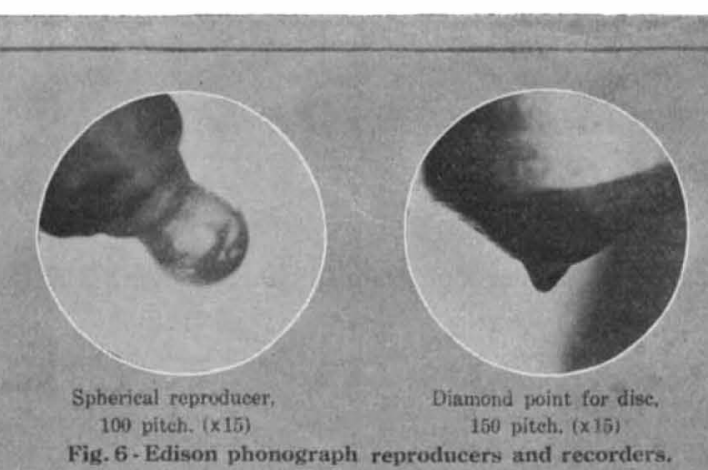

100 pitch. $(\times 15) \quad$ pitch. $(x) 15)$
Fig. 6 -Edison phonograph reproducers and recorders.

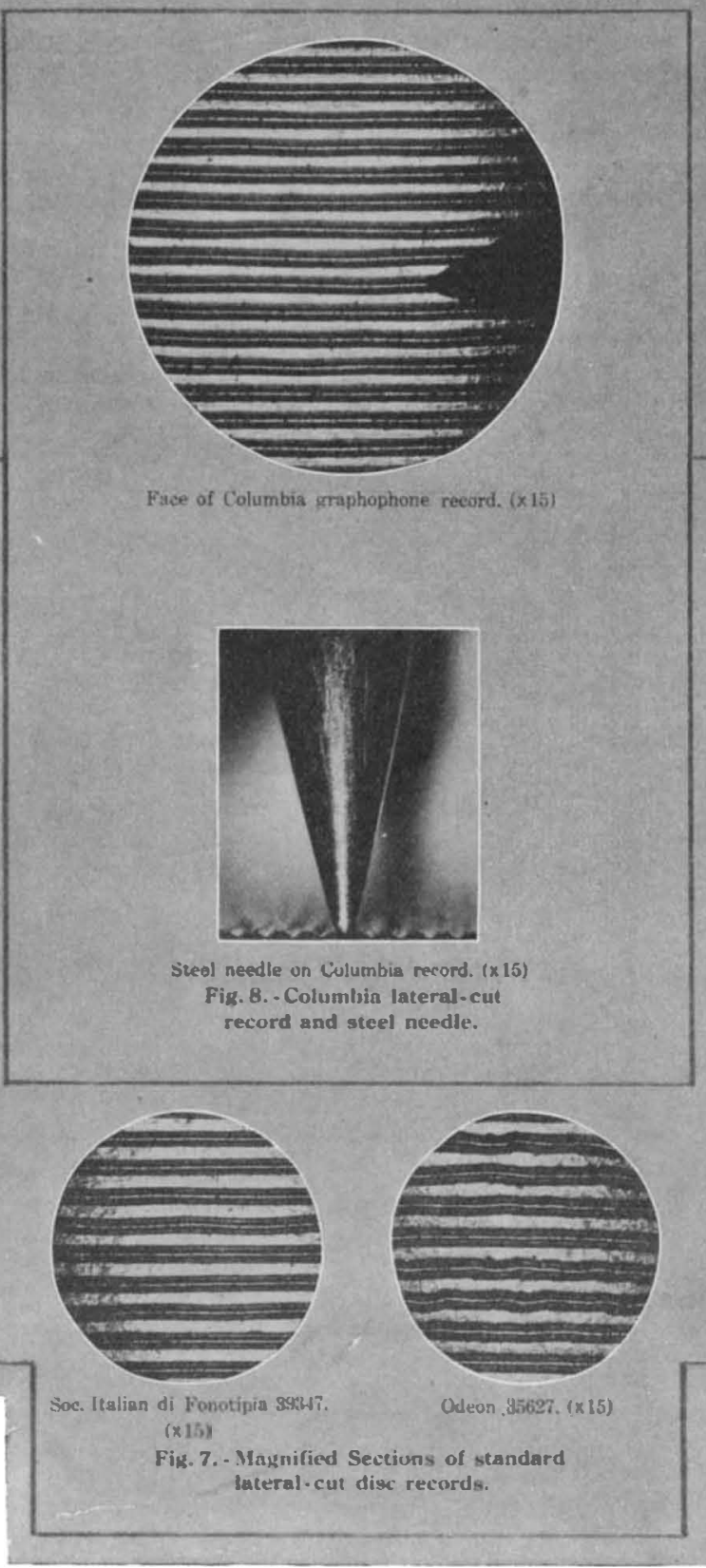

Lateral cut grooves and up-and-down recorders and reproducers.

separated by thin paper from the base or filling. The photo-micrographs show that the cross-section of groove is more like the curve of the end of an oval or a parabola than a circle. On loud, high pitched tones, where the frequency may run up to 2,000 or even 3,000 cycles, the needle is deflected from the sides of the groove twice this number. of times in every
second, and the forces on the needle and the sides of the second, and the forces on the needle and the sides of the
groove are considerable. A circular groove, unless groove are considerable; A circular groove, unless
approaching a semi-circle, would allow the needle to ride over the walls.

The foregoing considerations answer the question: Why cannot non-wearing materials like the diamond and sapphire be properly used on the side-to-side soundgroove type of record? For proper tone rendering, the stylus or needle must fit and fill the slot exactly: if too small, it will be thrown from side to side, giving false tones; if too big, it will give trouble by jamming and causing excessive wear of the record. The impracticability of making records and large numbers of jewels with grooves and points of duplicate and exact curvature and dimensions is practically met by using needles of steel or other material sufficiently soft to wear from an approximate to an exact fit in the first few revolutions of playing a piece, and yet sufficiently hard to play the whole of one or two records without wearing down to too extensive a shoulder bearing, or too long a base bearing for satisfactory tone rendering.

The narrow white line in the middle of the grooves of the photo-micrographs showing the faces of records may be mistaken as indicating a $\mathrm{V}$-shaped groove with a flat bottom. This line, however, is merely that portion of the curved surface so related to the source of light and to the image forming the objective that light is reflected from one to the other; and photographs can be made of the same record showing this line finer or broader by varying the source of light and working the numerical aperture of the microscope objective. Phonograph records approximate polished surfaces and are black besides, so examination and photographing is not easy since practically all the light returned is by specular reflection.

The wearing of a steel needle is shown in Fig. 9. Here magnification is $\mathrm{X} 25$, and side views of a needle show it when new and after playing a 12 -inch record once, twice and four times. A few calculations have been made for this test:

Weight on needle end, lb. .............. Area of needle end (approx. average), sq. in............
Weight per square inch, lbs........ 9,000 inch, lbs.............
D is t a n ce traveled, four records, feet.. 2,928 Average speed of record under needle, miles per hour.... 1.82 (2.73 m.p.h. max..91 m.p.h. min.) Thickness of steel worn off, inch..... 1-ฮ̄00 For best results, it is obvi ous that steel needles should be used to play but one record and then discarded. If the needle is not removed from the holder, a second playing of the same piece, as is often done when dancing, may not do serious harm. The unpardonable of fens.e against record property and proper phonograph usage is to place in the holder a neefile previously used. The point is then like a graving tool, and its sharp shoulders will almost certainly not be in proper position to fit the groove and will scratch the record badly until the playing has continued long enough to wear the needle to a new full bearing.

A record which has become worn by repeated playing and possibly by careless needle handling is shown magnified X25 in Fig. 10. A xylophone record was searcher until a note of high pitch and intensity was locaterl. This note is roughly the high $\mathrm{C}$ of the soprano, over 1.000 cycles per second. The sides of the groove, which bear the brunt of deflecting the needle with its at tached levers and diaphragm, shows clearly nicks in the edge of the groove. These nicks come alternately on opposite sides of the groove, about 1-100 inch apart and 1-2000 second later.

Several types of needle for lateral cut records are shown enlarged in Fig. 11. There are a large number of forms, types and makes of needles on the market and extravagant claims are made for many of them. Unless the possessor of high priced records knows, as a result of microscopic examination, the shape of the point and the character and extent of its wear, he will do well to avoid all novelties. "Permanent" or "multiplaying" needles in general for lateral cut records should be regarded with suspicion and used with great caution, for while there are types of needles which may not damage a record when used intelligently, the harder a needle and the less the wear, the greater 
The Dyestuff Famine.-II

A movement in this direction has been recently outlined by Mr. I. F. Stone, in the proposal to establish government-owne factories for the production of coal-tar intermediates. The various admirable features of the plan, including the wellorganized preparedness for the speedy generally, in case the nation be menace by invasion, render the project worthy of the most careful study.

Standardization of Dyestuffs and of the Methods of Their Application

A very distinct element of protection to a growing domestic color industry would undoubtedly result from the establishment of a Bureau of Standards for Dyestuffs. Such a bureau could be modeled after the admirable Division of Chemistry in the well-organized Bureau of standards, of the Department of Commerce. Its function would be to formu late the physical and chemical criteria of purity for all dyestuffs, exactly as is now done for the drugs listed in our pharmacopeia. In the laboratories of such a bureau,-and they would necessarily be rast,-it must be as easy and simple to check and control the tinctorial values of dyestuffs as we now do for our medicinals Such principles of standardization would likewise be applied to the varied methods of application on the diffeient fibres and other wares. A single, finelyequipped bureau could advantageously replace the multitude of laboratories now maintained by rival firms or in textile works. Such an institution could effectively protect a half-grown American industry against attempts to depreciate the quality and value of American-made dyes, and could insure a far greater degree of economy in cost of production than otherwise would be possible.

Everyone, familiar at all with the em ployment of colors in dyeing, can easily picture to himself the enormous advantages resulting from the impartial and exact classification and standardization of all coloring materials encountered in commerce, or the simplification, economy and certainty attendant upon their use in connection with all fibres and fabrics, as well as with leather, feathers, ink, paper, etc.

Instead of hundreds and thousands of isolated, blundering attempts to obtain the best dye for securing certain color results, the desired data could be requested by return mail from a national laboratory. If a dyer wishes to know exactly under what conditions, and in what quantities, a given dye should be employed to produce certain tinctorial effects upon a specific fibre, with a minimum expenditure of color, the full directions could be obtained, free of cost, with but little loss of time.

Organization of Consumers

Jogically, the complete standardization of existing dyestuffs, and of all additions to their numbers, as well as of the methods by which they can be most effectively and advantageously employed, should be a prelude to a vastly simpler and more economical method of merchandizing than is now the rule.

In possession of such a completely organized mechanism for saving time and effort in securing his current supply of colors, the dyer may naturally inquire: Why is it necessary to support a battalion of salesmen and middlemen, each seeking to disparage the quality of his rival's wares?

Here, we are touching upon a field of economic activity in which more than one experiment has indicated the practical value of collective buying and selling.

When hundreds of thousands of American farmers are able to purchase, at the lowest possible rates, their agricultural machinery, their binder twine, and $\mathrm{nu}$ merous other articles of daily use in a country home, why should not tens of thousands of consumers of colors utilize the same methods for covering their needs, at a minimum of outlay and a maximum of certainty as to strength and quality?

It would not be a difficult matter to organize into a compact body the con- sumers of colors, of all forms. Such a corporation would have for its object the purchase in quantities, at lowest wholeale rates, of all required dyes, and the distribution of such wares at cost price to the individual members. The actual expense to each member of such an or ganization would be almost negligible. Constituent members would be free to buy ny dyes in current use. The only re striction would be the absolute requirement that all purchases of colors should be made through a central agency, or one of its branches.

Such an agency would be backed up by the National Bureau of Dyestuff Standards in all current questions regarding purity, ease of application, etc. It would ensure the delivery to members, of dyestuffs of standardized strength and purity, t wholesale rates.

It can readily be appreciated to what n extent consumers of colors would be reed from all uncertainty and anxiety, regarding the price and character of their dyes. It can also be easily seen that a powerful weapon is put into the hands of those who collectively represent the consumers of colors, to rigidly rule out rom the sources of supply any manufacturer, foreign or domestic, who would deliberately make an attempt to undersell his American rivals, or who would resort of trade.

I harly need to dwell upon the farreaching effects of any such organization in protecting, to the utmost, the recognized rights of American producers and consumers of colors, and in providing the machinery for distribution at a minimum oxpense. It would be one of the most powerful bulwarks to ward off the daners of persistent and determined efforts, n the part of European rivals, to crush and stifle an American dyestuff industry. And such an industry we are bound to have! Our textile and other allied interests resolutely demand that they shall ever again be exposed to the disasters companying such a dyestuff famine as e now face. Such a powerful national rganization as the Association of Hosiery Manufacturers unanimously resolved that it would willingly bear the burden of origin, if that be necessary, to insure the stablishment upon American soil of a omestic, self-contained industry.

American chemists insist that the one great branch of color chemistry, now lacking in the cycle of our national industries, should be established in all its ramifications upon our soil, and that American chemical technology should no longer be o conspicuously lacking in the most britliant feature of applied science.

Before the advent of this deplorable war, we imported annually about 2,500 short tons of aniline oil and aniline salts. In 1916, over 5,000 tons will be manufactured on American soil, from American oal-tar crudes. In 1913, our American color works produced 3,000 short tons of coal-tar colors, made chiefly from German intermediates. We imported 25,600 tons of these colors, of which 22,000 tons came from Germany.

To-day we are making nearly 9,000 tons of these colors. January, 1917, should see n American production of at least 16,000 tons. Am I too optimistic in confidently looking forward to the year 1920 as ate, when the great bulk of artificia dyes, consumed in this country, will be made in American works, from American aw material, by American labor

Microscopic Study of the Phonograph (Concluded from page 429 .)

the damage to the record if the needle is removed from the holder and replaced in a different position. At $F$, Fig. 11, is sown a multiplaying needle formed from public as solving the needle problem. If the form of the point of this needle is traced on a piece of paper and this cut out carefully and placed in one of the grooves of the record shown in Fig. 8-the scale of magnification being near enough -it may be seen that it does not fit the roove but bears wholly on the sharp point

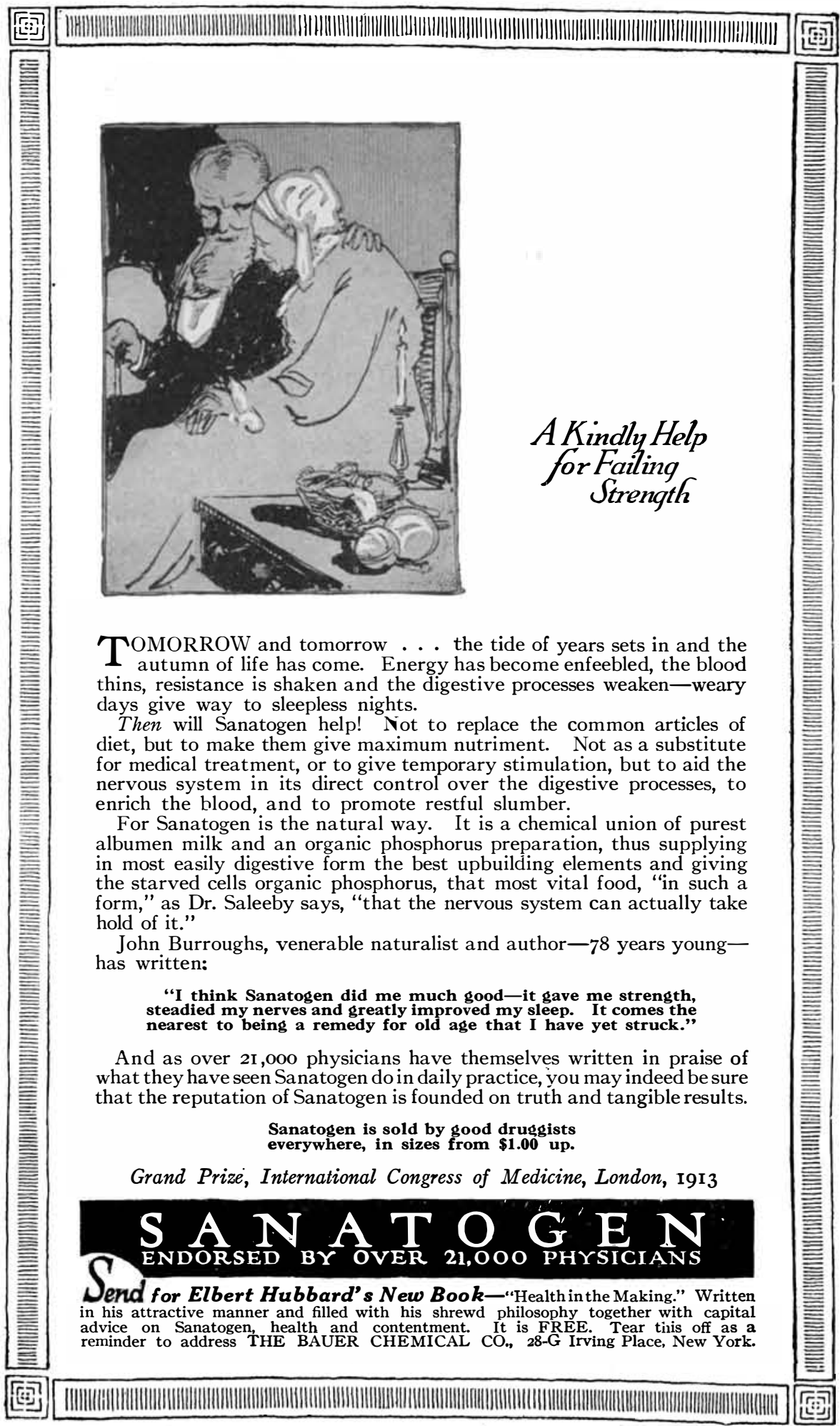

John Hampstead, railroad clerk, actor, book agent, preacher - here is a new character that will live in American fiction.

"HELD TO ANSWER" is a really big, emotional, American novel by Peter Clark Macfarlane. The author's sincerity of purpose, his skillful handling of interesting characters and his development of dramatic climaxes cannot fail to make a deep impression on the reading public. The first chapters of "HELD TO

ANSWER" will appear in the

Novem ber Twentieth issue of

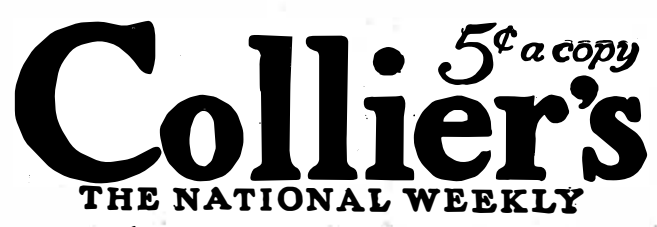

${ }_{416}$ West 13th Street, New York City 
LEG A L NOT ICE S

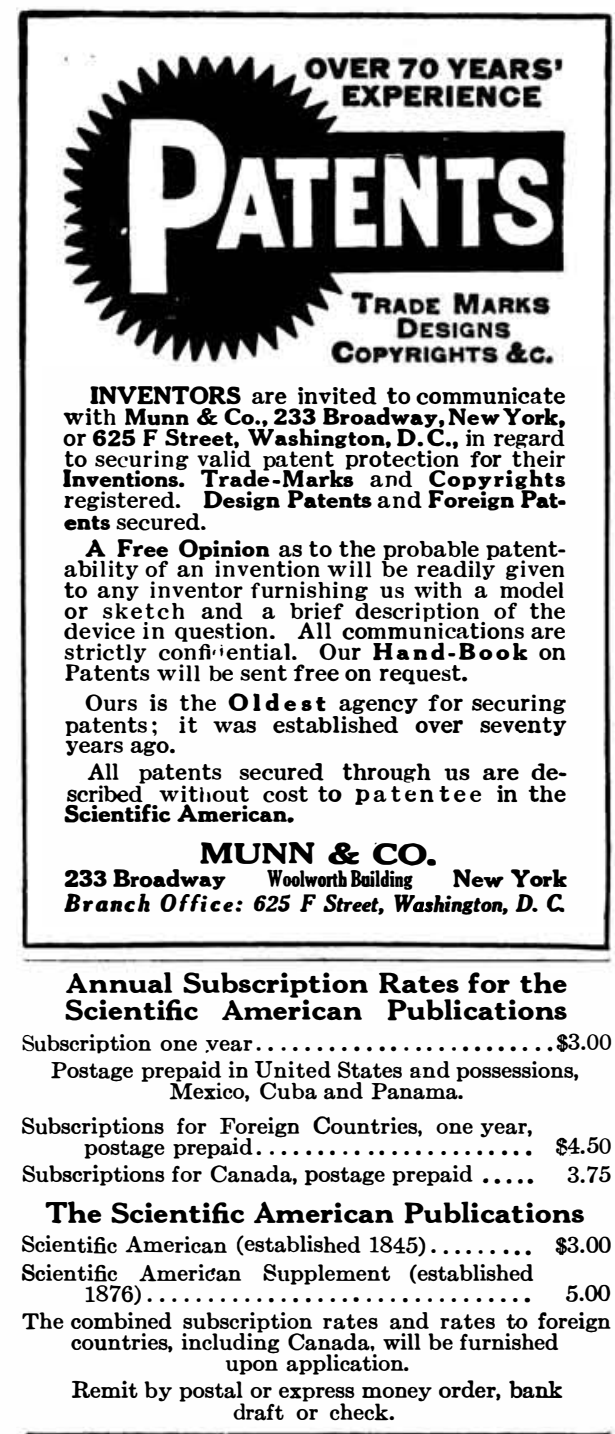

Classified Advertisements

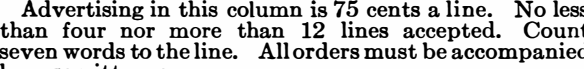

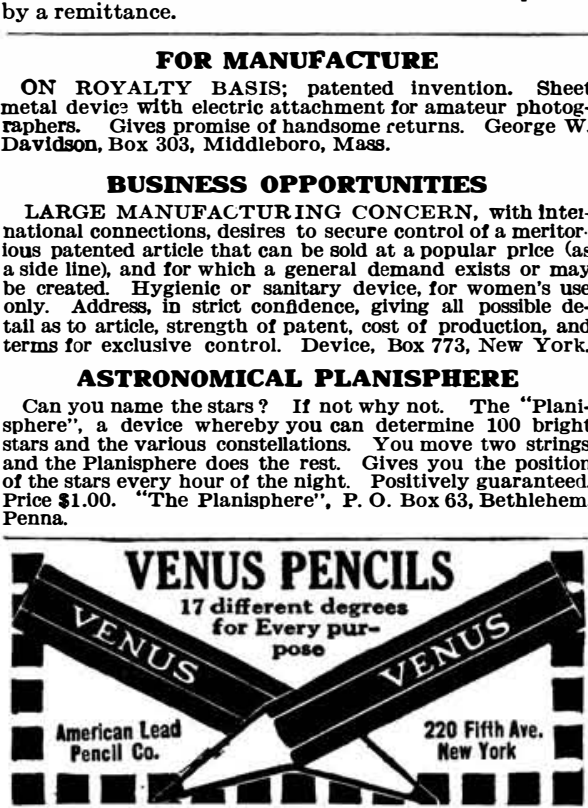

LEARN TO BE A WATCHMAKER Bradley Polytechnic Inetitute- -
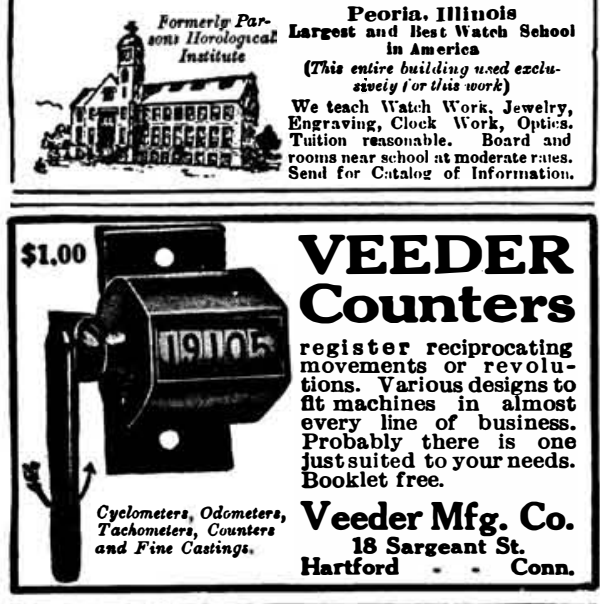

11,572-Word Business Book Free Simply send us a postal and ask for our free illustrated
11,572 -word Business Booklet
Bhich tells how priceless 11,572-mord Business Booket whicm the lives of 173 big.
Business Experience, squeezed from the
broad, brainy business men, may be made yours - yours to

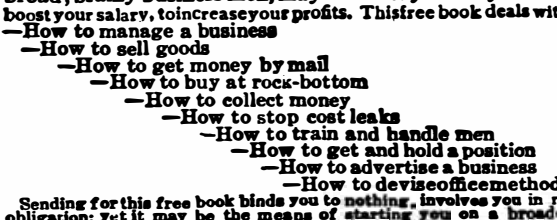

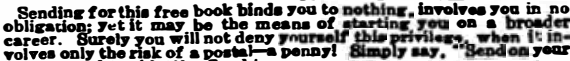

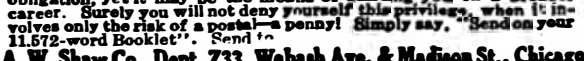

The keen interest in better aeroplane engines is not confined to the European countries now at war, for in the United States there has been considerable activity in the matter of encouraging the development of heavier-than-air craft engines, in the recent past.

At the urgent request of the Army and Navy Departments, much attention is beng given to engine problems by variou aeronautical boards and organizations. Prof. Charles Edward Luckey, of Coumbia University, who is investigatin the aeroplane engine situation for th National Aeronautic Advisory Board, at tended a recent meeting of the Aerodiscussions on the requirements of preent-day aeroplane engines, as well as on the deficiencies of many of the existing types. Two of the new American twelve cylinder engines, the Aeromarine an Rausenberger, were described at the meetfortunately, the designers were too preoccupied to be present and answer questions. At the meeting, Prof. Luckey ad anced a strong plea for the standardization of aeroplane engines.

It is believed among aeronautical me that should a contest for aeroplane motor be held by the Navy, in the near future as has been recommended, the probabilties are that more than one of the "twinsix" types will be found among tho seeking the honors.

Science as an Aid to Practical Tennis (Continued from page 430.)

scientific statement of fact. Johnston is living evidence that science and practical tennis may be in close accord.

There are, of course, limits beyond which science may not help the player. We are obliged to compromise continually innoring mechanical science altogether. Take the law of the lever, for instance and apply it in the backhand grip. The thumb straight along behind the handle is supposed to act as an additional support and to strengthen the direct blow. It does not. It weakens it. The law of of lever offsets the apparent increase plicable with the thumb along the handle is 19 per cent less than with the thumb diagonally or straight around in a grasping position. This is the average obtained in a great many actual tests. The thumb stif, and as the force applied becomes off the handle, throwing all of the thumbpressure out to the end. The leverage here is so much more than at the base of the thumb that it is not possible for the normal man to exert as great pressure with the thumb along the handle as with the thumb grasping it and thus bringi Then, take the mechanical formala the the force of a blow equals half the mass multiplied by the square of the velocity. The faster the ball, the harder it hits, of course, but few realize that an increase of only one half in speed will more than equally to the swing of the racket, so that if we can double the speed of the swing we get four times the force in the blow-not merely twice the force. So it is plain that, as we rotate the body, we may get much more force in the blow by keeping the racket away from the body, so that it swings

But science again steps in and warns us of the limit to which this swing may be carried, and shows the difficulty of swinging the 14-ounce racket fast enough to equal the force of the mile-a-minute ball. It would have to swing at about the rate of 40 feet a second to absorb all the shock itself. Otherwise, the hand and arm must supply a large part of the igidity at the instant of contact. Forty feet a second is beyond the power of the average player, so the shock on the hand is great and requires a rigid arm to withstand. A rigid muscle moves jerkily, tending to make the shot wild; and the only benefit one derives from a wild shot is the unselfish satisfaction of presenting the point to one's opponent.

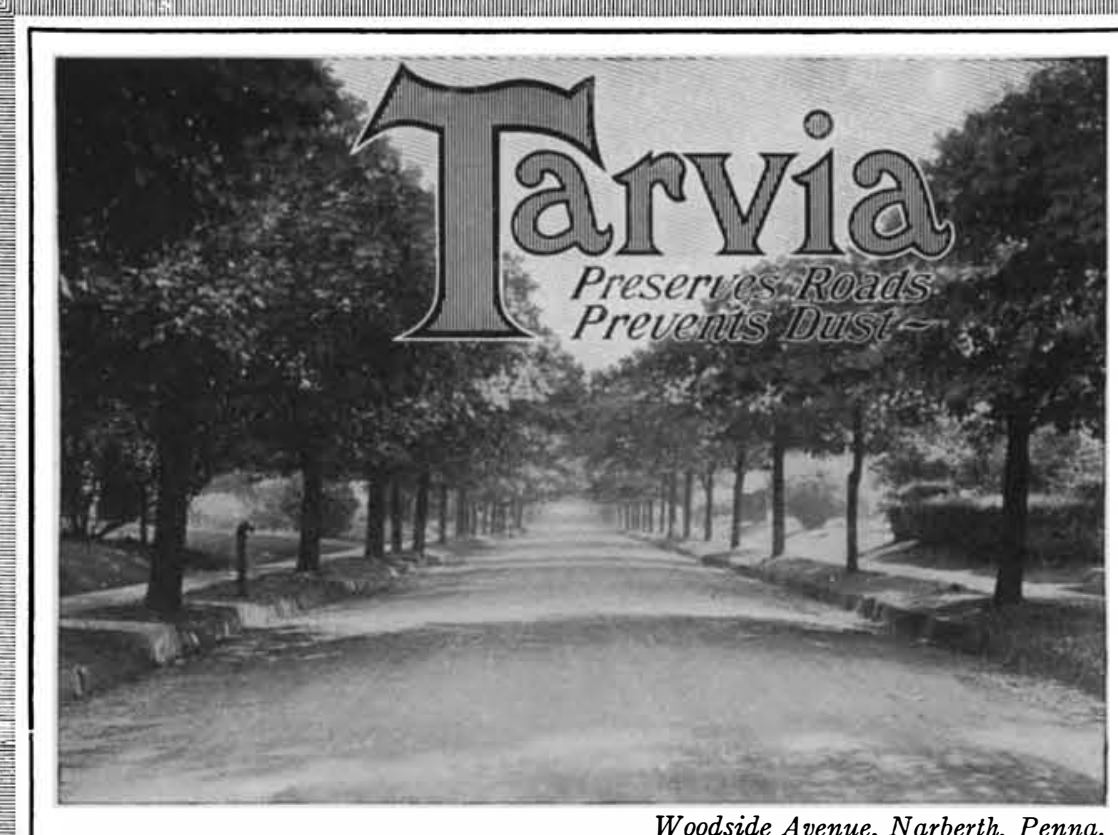

Woodside Avenue, Narberth, Penna.
Treated with "Tarvia-B".

Narberth's Experience with Tarvia-

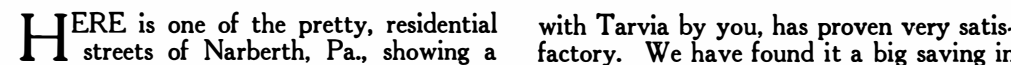
stretch of macadam which was treated in factory. We have found it a big saving in 1915 with "Tarvia-B" to make it dustless, seetling the dust. The best recommendadurable and automobile moof.

"Tarvia-B" is a coal tar preparation which is applied, inexpensively, without heating. It reinforces the top surface of the macadam
and adds greatly to the life of the roadway and adds greatly to the life of the roadway
-so much so that its use is a real economy Name as the result of a test which Wear. We predict that Narberth will be Highway Committee of Narberth, writes: which make the use of Tarvia a steady prac"The 50,000 yards of macadam, treated tice year after year.

Illustrated booklets on request. Address our nearest office

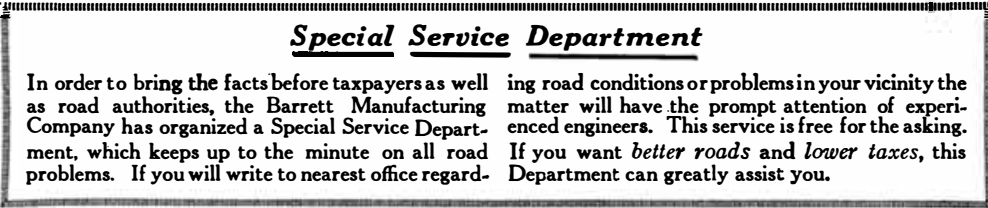

BARRETT MANUFACTURING COMPANY

New York Chicago Philadelphia Boston St. Louis Cleveland Cincinnati Pittsburgh
Detroit Birmingham Kansas City Minneapolis Salt Lake City Seattle Peoria
THE PATERSON MFG. Co. Limited: Montreal Tornento Winnipeg Vancouver
St. John, N. B. Halifax, N. S. Sydney. N. S.

\section{Harper's A-B-C Series}

\section{A-B-C OF}

ELECTRICITY

By William H. Meadowcroft

Author of "The Boy's Life of Edison"

The author explains the various ways by which electricity is obtained wireless telegraphy, the telephone, teries are all treated in separate divisions with the utmost clarity.

\section{A-B-C OF}

\section{HOUSEKEEPING}

By Christine Terhune Herrick

This book gives an outline of the details essential for a young housekeeper in order that her home-making may be a success; the choice of a and economy in buying and cooking,

\section{A-B-C OF \\ GOOD FORM}

\section{By Anne Seymour}

Presents in the simplest form the facts about our formal relations with our fellows which every one needs to "Visiting-Calls, Regrets"; "Weddings"; "Card Parties"; "Good Form in Dress," are among the topics.

\section{A-B-C OF GARDENING}

By Eben E. Rexford

This book on gardening contains all the information necessary for startin and keeping in order an outdoo flower-garden or indoor plants. Here is the manual for those who sigh to have growing things about, but who are bewildered by the numberless directions of so many volumes on the subject.

\section{A-B-C OF}

\section{ARCHITECTURE}

\section{By Frank E. Wallis}

Author of "How to Know Architecture"
This little book simplifies the rules and laws of architecture so that it basic principles can be readily understood. It is written for those inquisitive folk who wish to know the periods and styles in architecture, and the relation which they bear to on another. The author, who is an architect in actual practice, has added explanatory illustrations.

Illustrated.

\section{HARPER \& BROTHERS}

